\title{
Geometria e educação infantil: um estudo de inspiração etnomatemática
}

Geometry and Pre-school education: a study with ethnomathematical inspiration

\author{
Ediana Cimadon ${ }^{1}$
}

Ieda Maria Giongo ${ }^{2}$

\section{Resumo}

O presente texto aborda um conjunto de resultados advindos de uma prática pedagógica investigativa realizada com crianças do Jardim B (Pré-escola) de uma Escola Municipal Infantil localizada no Rio Grande do Sul. Seu objetivo é problematizar os saberes que emergiram quando as crianças foram postas em contato com tarefas vinculadas às Noções Geométricas Espaciais. De cunho qualitativo e inspirações etnográficas, a investigação tem como referencial teórico-metodológico o campo da Etnomatemática, interessado em examinar questões sociais e culturais no âmbito do ensino. $O$ material de pesquisa foi composto pelo diário de campo da professora/pesquisadora, gravações de vídeo, material produzido pelos estudantes, tais como desenhos, maquetes e construções. A análise efetivada sobre o material de pesquisa evidenciou que as crianças se utilizaram de diferentes estratégias para operar com noções de volume. Tal resultado pode ser produtivo para que saberes gerados nessa faixa etária possam ser problematizados com vistas à qualificação do ensino de Matemática na Educação Básica.

Palavras-chave: Ensino de Matemática; Etnomatemática; Educação Infantil; Geometria Espacial.

\section{Abstract}

This text approaches a set of outcomes originated in an investigative teaching practice carried out with the children of the Kindergarten B (preschool) in a Municipal Children School located in Rio Grande do Sul (Southern Brazil). Its purpose is problematizing the knowledge that emerged when children were put in touch with tasks connected with Notions of Spatial Geometry. With a qualitative nature and ethnographical inspiration, the investigation has the field of Ethnomathematics as its theoretical-methodological framework; this field focuses on social and cultural aspects within teaching. The research material is constituted by the teacher/researcher's field journal, video shootings, materials produced by the students, such as drawings, models and constructions. The analysis of the research material has shown that children used diverse strategies to operate with notions of volume.

\footnotetext{
${ }^{1}$ Secretaria Municipal de Educação de Bento Gonçalves | edianacimadon@live.com

${ }^{2}$ Universidade do Vale do Taquari - Univates | igiongo@univates.br
} 
Such an outcome may be productive in that the knowledge produced within this age range may be problematized, thus qualifying the teaching of Mathematics in Basic Education.

Keywords: Teaching of Mathematics; Ethnomathematics; Children Education; Spatial Geometry.

\section{Introdução}

É nos primeiros anos de vida que a criança reconhece o mundo à sua volta e, a partir das vivências, constrói a sua identidade. Portanto, a Educação Infantil é etapa fundamental na construção do conhecimento, pois é, nesta fase, que elas exploram seu meio e fazem as descobertas por meio das brincadeiras. Além das diversas habilidades e conceitos que devem ser desenvolvidos nesta faixa etária, cabe ressaltar a importância do ensino da Matemática, uma vez que, se bem abordadas, as aptidões matemáticas poderão amparar seus próximos anos de vida escolar e também a solucionar desafios que encontrarão no dia a dia.

Frequentemente, evidencia-se a lacuna deixada nos conteúdos que englobam as Noções Geométricas Espaciais, pois a maior preocupação tem estado relacionada à construção do numeral, à contagem numérica e à nomeação e caracterização de figuras geométricas. Em meio a tantas inquietações, passamos a nos questionar sobre o porquê de os professores de Educação Infantil pouco explanarem o estudo da Geometria Espacial. Ademais, percebemos, a partir de resultados de pesquisas do campo da etnomatemática, que

\footnotetext{
[...] a Etnomatemática também põe em questão a Matemática Escolar, com as marcas de transcendência que herda da Matemática Acadêmica produzida pelos que têm a profissão de matemáticos. [...] Mas seu interesse, ao examinar as outras Etnomatemáticas que não a Etnomatemática Acadêmica teve - e ainda tem - como horizonte a Matemática Escolar (KNINIK et al., 2012, p. 25).
}

Nesses últimos anos, vivenciamos inúmeras situações de curiosidade e imaginação demonstradas pelas crianças que, quando desafiadas, passavam a reconstruir saberes que já possuíam e a compreender outras situações e, assim, aperfeiçoavam suas aptidões. O processo de construção de habilidades matemáticas se desenvolve em diversas situações, mas principalmente na faixa etária de zero a seis anos. Esse processo ocorre nas vivências, interações com demais sujeitos e objetos e brincadeiras, tornando-se uma ação ininterrupta e constante. As inquietações sobre o ensino da Geometria Espacial na Educação Infantil e as implicações provenientes da abordagem desse conteúdo fizeram-nos refletir como versar Noções Geométricas Espaciais, como elas influenciariam a construção de conhecimento e quais noções e conteúdos devem ser explorados nesse nível de ensino.

Smole, Diniz e Cândido (2003) inferem que a criança está inserida em um contexto social que the possibilita diversas informações e que, em sua maioria, são geradas e 
percebidas pela exploração do espaço ao seu redor. Percebe-se que elas são carregadas de conhecimentos e que, essencialmente, envolvem noções espaciais. As autoras ainda apontam que, para que a percepção do espaço se torne cada vez mais elaborada, a criança necessita ver e apreciar a Geometria em seu mundo, descobrir formas, desenhá-las, escrever e falar sobre elas (SMOLE; DINIZ; CÂNDIDO, 2003).

Nessa mesma direção, Fonseca et al. (2002, p. 93) pressupõem que a formação humana geral tem como importante item o estudo da Geometria, pois promove "valores culturais e estéticos importantes para uma melhor compreensão e apreciação das obras do homem (construções e trabalhos artísticos) ou da natureza". Os autores ainda mencionam dois objetivos básicos para o ensino da Geometria na Escola Fundamental:
O primeiro, a princípio mais ligado à dimensão instrumental, mas que envolve um conceito básico na construção do edifício da Matemática, é o desenvo/vimento da capacidade de medir. O segundo, integrado à dimensão formativa, já que se reporta a habilidades básicas de percepção e classificação, mas que figura como alicerce para o exercício de quaisquer atividades que demandem competências geométricas, é o desenvo/vimento da capacidade de pesquisar regularidades (FONSECA et al., 2002, p. 93, grifos dos autores).

Considerando que a Geometria Espacial é inerente ao contexto infantil, compreendemos que os saberes oriundos da cultura da criança estarão presentes em sua vida escolar. Em vista disso, aproximamo-nos do campo da Etnomatemática, pois
O pensamento etnomatemático está centralmente interessado em examinar as práticas de fora da escola, associadas a racionalidades que não são idênticas à racionalidade que impera na Matemática Escolar [...]. Mas é preciso que se diga: olhar para essas outras racionalidades, sem jamais se esquecer do que está no horizonte, é pensar outras possibilidades para a Educação Matemática praticada na escola (KNIJNIK et al., 2012, p. 18).

Ao aliar a Etnomatemática a Noções Geométricas Espaciais com alunos da Educação Infantil, verifica-se que a Geometria Espacial está presente no cotidiano e, por isso, podem emergir distintas formas de pensamento. Na busca por autores que explanassem a importância da abordagem da Geometria Espacial com crianças dessa faixa etária e que pudessem sustentar esta pesquisa, deparamo-nos com o livro Figuras e Formas: Matemática de 0 a 6 anos, de Smole, Diniz e Cândido (2003). Nessa obra, as autoras demonstram que explorá-la nessa idade proporcionará às crianças percepções do espaço físico em que estão inseridas, além de desenvolverem Noções Geométricas que as prepararão para estudos mais formais da Geometria.

A Etnomatemática possibilita averiguar essas distintas formas de aprendizagem, uma vez que, apesar de diferentes, estão corretas e também produzem conhecimento. Dessa forma, D’Ambrósio (2002b, p. 28) pressupõe que cada indivíduo percebe a realidade à sua 
maneira, sendo esta

[...] acrescida da totalidade de artefatos e de mentefatos [experiências e pensares], acumulados por ele e pela espécie [cultura]. Essa realidade, através de mecanismos genéticos, sensoriais e de memória [conhecimento], informa cada indivíduo. Cada indivíduo processa essa informação, que define sua ação, resultando no seu comportamento e na geração de mais conhecimento.

Ao considerar a abordagem da Geometria Espacial na Educação Infantil, os processos de ensino e de aprendizagem devem estar associados a situações que façam sentido às crianças, pois é nessas experiências que elas fazem relação com seu cotidiano. D’Ambrósio (2002b, p. 46) afirma que "A proposta pedagógica da etnomatemática é fazer da matemática algo vivo, lidando com situações reais no tempo [agora] e no espaço [aqui]. E, através da crítica, questionar o aqui e agora".

Ao apontar a relevância de proporcionar atividades que englobam as Noções Geométricas Espaciais na Educação Infantil, o presente artigo é um excerto da pesquisa de uma dissertação de Mestrado que visa relatar vivências obtidas a partir de uma prática com crianças de Educação Infantil, com faixa etária de cinco e seis anos de idade. A vivência a seguir relatada faz parte de uma das atividades desenvolvidas para abordar o Ensino da Geometria Espacial na faixa etária descrita a partir de uma proposta Etnomatemática.

\section{Educação Infantil e Geometria Espacial: tecendo um referencial teórico com o campo da Etnomatemática}

O cotidiano está impregnado dos saberes e fazeres próprios da cultura. A todo instante, os indivíduos estão comparando, qualificando, quantificando, medindo, explicando, generalizando, inferindo e, de algum modo, avaliando, usando os instrumentos materiais e intelectuais que são próprios à sua cultura (D'AMBRÓSIO, 2002b, p. 22).

Analisando o excerto acima e estudos e leituras de autores e bibliografias que sustentam esta investigação, percebemos a relevância de desenvolver os diferentes conceitos e habilidades relacionados à Geometria Espacial visando à interação com a cultura das crianças. Ao pensar em culturas e Matemática, evidenciamos o entrecruzamento da problemática e de aproximações com o campo da Etnomatemática, uma vez que as crianças são seres carregados de conhecimentos via suas vivências, relacionados diretamente com noções de Geometria Espacial.

Ao considerar o contexto escolar no qual a intervenção pedagógica foi realizada e pensando essencialmente na Educação Infantil e nas distintas culturas provenientes dos diversos grupos familiares que compõem a comunidade escolar, entendemos que os estudos da Etnomatemática possibilitaram a análise de como esse grupo de crianças 
pensava matematicamente.

Há muitas discussões acerca da importância da Educação Infantil ${ }^{3}$ nos processos de construção dos conhecimentos das crianças e os conteúdos que devem ser explorados na faixa etária de zero a seis anos de idade. O Referencial Curricular Nacional (BRASIL, 1998) já se preocupava com a Educação Infantil e, mais recentemente, a Base Nacional Comum Curricular $^{4}$ (BNCC), pensando na unificação dos currículos no país, aborda a Educação Infantil como etapa fundamental da educação. Optamos por centrar os estudos na Base Nacional Comum Curricular porque a escola na qual foi realizada a intervenção considerava realizar a reestruturação da Proposta Pedagógica.

Na BNCC (2017), apresentam-se os objetivos, as competências e as experiências de aprendizagem que devem ser desenvolvidos. Ao analisar os itens "Campos de Experiências" (BRASIL, 2017, p. 38), organizados em O eu, o outro e o nós; Corpo, gestos e movimentos; Traços, sons, cores e formas; Escuta, fala, pensamento e imaginação; Espaços, tempos, quantidades, relações e transformações; percebemos que os conteúdos relativos à Geometria podem ser abordados em todos os Campos de Experiências.

Ao estudar a BNCC, percebe-se a preocupação com relação à Educação Infantil e como o processo de ensino e de aprendizagem considera os conhecimentos oriundos das vivências adquiridas nos ambientes familiares. Duhalde e Cuberes (1998), em sua obra, refletem sobre a Matemática nas escolas infantis e destacam que a maior parte das crianças nasce e convive "em um mundo no qual o número é uma forma de expressão e comunicação com sentido: a troca, a compra, a venda, a resolução que têm a ver com a reunião e a distribuição de objetos que formam parte da cultura adquirida na infância" (DUHALDE; CUBERES, 1998, p. 30). É importante atentar que elas, ao chegarem na "escola infantil possuem muitas noções matemáticas informais que provêm do meio familiar" (DUHALDE; CUBERES, 1998, p. 35). As autoras acrescentam que o ingresso na escola infantil determina um processo exclusivamente do contexto familiar a um influenciado pela escola e sociedade, e que este deve ser levado em consideração pelos educadores (DUHALDE; CUBERES, 1998).

Assim, surgem inúmeras preocupações sobre quais conceitos e habilidades matemáticas uma criança de zero a seis anos deve construir para que consiga solucionar problemas de seu cotidiano e estabelecer relações em seus próximos anos de vida escolar. Compreendemos que ela é um "ser que observa, questiona, levanta hipóteses, conclui, faz julgamentos e assimila valores e que constrói conhecimentos e se apropria do

\footnotetext{
${ }^{3}$ A presente pesquisa não tem por pretensão analisar todo âmbito da Educação Infantil, desse modo, abordarei uma seção que dá enfoque à Geometria Espacial com crianças da Educação Infantil.

${ }^{4}$ Como prevista em constituição, o MEC elaborou uma Base Nacional Comum (BNCC) que aborda um capítulo sobre a Educação Infantil e foi aprovada em dezembro de 2017.

Fonte: <http://g1.globo.com/educacao/noticia/base-nacional-comum-curricular-bncc-e-aprovadaem-conselho.ghtml.> Acesso em: 20 dez. 2017.
} 
conhecimento sistematizado por meio da ação e nas interações" (BRASIL, 2017, p. 36) e, ao chegar no ambiente escolar, traz consigo habilidades que se unificam com habilidades acadêmicas, e "a instituição precisa conhecer e trabalhar com as culturas plurais, dialogando com a riqueza/diversidade cultural das famílias e da comunidade" (BRASIL, 2017, p. 35).

Essas questões provocam inquietações, uma vez que as crianças dessa faixa etária têm curiosidade e podem contribuir com suas próprias vivências para elaborar diferentes conceitos matemáticos. Elas trazem de suas experiências noções que devem ser consideradas ao se pensar o ensino da Matemática. Sobre a Geometria Espacial, Dienes e Golding (1969) pressupõe que a "Geometria é a exploração do espaço", e que a criança o explora desde seu nascimento (DIENES; GOLDING, 1969, p. 1). Ao elaborarmos propostas relacionadas com sua cultura, damos sentido e significado ao que está sendo abordado. Como afirmam Smole, Diniz e Cândido (2003, p. 9),
Uma proposta desse tipo incorpora os contextos do mundo real, as experiências e a linguagem natural da criança no desenvolvimento das noções matemáticas, sem, no entanto, esquecer que a escola deve fazer o aluno ir além do que parece saber tentando compreender como ele pensa, que conhecimentos traz de sua experiência no mundo e fazendo inferências no sentido de levar cada aluno a ampliar progressivamente suas noções matemáticas.

Quando possibilitamos aos estudantes a explanação de suas ideias, além de proporcionar atividades relacionadas ao seu cotidiano, levamo-los a buscar analogias com distintas áreas e, assim, expandir conhecimentos. Fainguelernt (1999, p. 51) destaca que a Geometria deve ser abordada desde os primeiros anos de escolaridade, de modo que o aluno possa estabelecer relações com o espaço que o envolve, viabilizando a "construção de um caminho que o ajudará a fazer a passagem do estágio das operações concretas para o estágio das operações abstratas" (FAINGUELERNT, 1999, p. 51).

Dienes e Golding (1969, p. 1) apontam que os conceitos geométricos não se ensinam, o que pode ser feito é criar, proporcionar situações e vivências que auxiliarão as crianças a formá-los. Estas "desenvolvem noções espaciais desde muito cedo, quando ficam curiosas com o espaço ao seu redor e nele interagem" (ZOGAIB; SANTOS-WAGNER, 2017, p. 52).

Ao refletir sobre a criança como sujeito ativo, que aprende e interage, considera-se que, nesta fase, inicia a edificação de importantes habilidades. Assim, ela será capaz de construir, reconstruir e se apropriar de saberes importantes para a formação humana e do convívio em sociedade. Zogaib e Santos-Wagner (2017, p. 52) pressupõem que as crianças "mesmo da escolarização, vão processando suas ideias sobre as formas e o espaço e utilizando o conhecimento matemático/geométrico, ainda que de forma intuitiva".

A Geometria Espacial, por se referir a um tema que é inato à criança, quando abordada em conceitos de espaço, formas e dimensões, trará relações com situações que são habituais com o espaço, como construir, mover-se, deslocar-se, dentre outros. É na Educação Infantil que devem ser propostos momentos significativos para que os alunos 
desenvolvam a habilidade de controle sobre suas ações e, assim, possam solucionar problemas, potencializando o aprimoramento do pensamento geométrico. Como justificam Smole, Diniz e Cândido (2003, p. 16), "a abordagem da geometria na escola infantil não deve estar restrita a tarefas de nomear figuras, mas fundamentalmente voltada para 0 desenvolvimento das competências espaciais das crianças". A Educação Infantil "precisa promover experiências nas quais as crianças possam fazer observações, manipular objetos, investigar e explorar seu entorno, levantar hipóteses e consultar fontes de informação para buscar respostas às suas curiosidades e indagações" (BRASIL, 2017, p. 41).

Dessa forma, ao criar "oportunidades para que as crianças ampliem seus conhecimentos do mundo físico e sociocultural e possam utilizá-los em seu cotidiano" (BRASIL, 2017, p. 41), percebe-se que o ambiente em que vivemos não é bidimensional, pois pensar em objetos planos, que não têm profundidade, é quase impossível, uma vez que vivemos em um mundo no qual tudo é tridimensional, até nós mesmos não somos seres planificados. Por isso, é mais fácil e mais significativo abordarmos conteúdos que apresentem relação com os conhecimentos das crianças.

[...] o objetivo principal do ensino de Geometria nas séries/ciclos iniciais é a percepção e organização do espaço em que se vive. Considerando que esse espaço sensível é tridimensional, a proposta é iniciar-se o estudo da Geometria pela observação desse espaço e pelos modelos que o representam (FONSECA et al., 2002, p. 28)

Ao conseguirem explorar os espaços, saberem se organizar em relação aos objetos que surgem, as crianças formalizam pensamentos que as tornam capazes de solucionar desafios e aprovar novidades que surgem. Além disso, Noções Geométricas ${ }^{5}$ podem, posteriormente, facilitar a compreensão da Geometria. Ao inserir-se num espaço, a criança passa a interpretá-lo e a organizá-lo a partir das suas percepções de mundo, e essas habilidades também a auxiliarão a organizar os seus pertences, por exemplo.

A criança é um sujeito imerso de informações, conhecimentos e bagagem cultural, adquiridos em suas vivências e, ao frequentar a pré-escola, ela expressa aos demais o que sabe, o que viu e o que experimentou. Essas diversidades de vivências devem ser levadas em consideração ao abordarmos os diferentes conteúdos no processo de aprendizagem. Assim, por se tratar de alunos de cinco e seis anos, acreditamos ser relevante, entre outros aspectos, atentar para o que eles sabem e dizem durante a realização das atividades de Geometria Espacial. Percebemos que há, "racionalidades diferentes operando na Educação Matemática praticada na escola e fora dela: a Matemática Escolar tem como marca a transcendência e as práticas fora da escola são marcadas pela imanência" (KNIJNIK et al., 2012, p. 17 - 18).

Desse modo, o campo da Etnomatemática possibilita analisar os saberes matemáticos 
que se manifestam nas distintas relações entre os seres humanos, abrindo inúmeras possibilidades, uma vez que cada indivíduo convive em diversos contextos culturais e pode contribuir com seus conhecimentos para a coletividade, de modo que a Etnomatemática "está interessada em examinar a diferença cultural no âmbito da Educação Matemática" (KNIJNIK et al., 2012, p. 26). De fato, a Etnomatemática tenciona analisar a Matemática Escolar e também as matemáticas praticadas por grupos sociais e culturais. Knijnik (2004, p. 22) retrata que os estudos desse campo proporcionam "a tarefa de examinar as produções culturais. Dessa forma, para a Etnomatemática, considerando o contexto dos alunos, é possível relacionar os conhecimentos produzidos nos ambientes familiares com os saberes produzidos no espaço escolar.

Em vista disso, acreditamos que a investigação das Noções Geométricas Espaciais praticadas por crianças dessa faixa etária (cinco e seis anos de idade) em suas vivências, possibilitará a interação com estudos do campo da Etnomatemática, uma vez que contemplará as distintas formas de pensar das crianças. A bagagem cultural que cada um traz não pode ser considerada congelada, mas sim um conjunto de aprendizagens que provocam outras e, assim, ampliam-se os conhecimentos.

Neste sentido, ao analisar a intervenção por meio do campo da Etnomatemática, muitas atividades apresentaram resultados imprevisíveis, pois a área considera as culturas sempre em evolução e modificação. Knijnik et al. (2012, p. 26) pressupõem que,

Para a Etnomatemática, a cultura passa a ser compreendida não como algo pronto, fixo e homogêneo, mas como uma produção, tensa e instável. As práticas matemáticas são entendidas não como um conjunto de conhecimentos que seria transmitido como uma "bagagem", mas que estão constantemente reatualizando-se e adquirindo novos significados, ou seja, são produtos e produtores da cultura.

Assim, compreendemos que os produtos resultados da prática podem contemplar distintas formas de pensamento e também outras áreas do conhecimento. Nessa perspectiva, D'Ambrósio (1998, p. 8) evidencia que a origem inicial de conhecimentos é a realidade na qual estamos concentrados; o conhecimento se manifesta de maneira total, holisticamente e não seguindo qualquer distinção disciplinar. Ainda para o autor, as crianças, desde o nascimento, trazem conhecimentos apreendidos em suas vivências e nas relações com a família, existindo uma conexão com as diversas áreas do conhecimento, sem a fragmentação das disciplinas. Desse modo,

O Programa Etnomatemática não se esgota no entender o conhecimento [saber e fazer] matemático das culturas periféricas. Procura entender o ciclo da geração, organização intelectual, organização social e difusão desse conhecimento. Naturalmente, no encontro de culturas há uma importante dinâmica de adaptação e reformulação acompanhando todo esse ciclo, inclusive a dinâmica cultural de encontros [de indivíduos e de grupos] (D'AMBROSIO, 2002a, p. 13). 
Ao pensar em abordar a Geometria Espacial com crianças de cinco e seis anos de idade, é essencial demonstrar que esse conteúdo está presente em nosso cotidiano. Não terá sentido nenhum falar em sólidos geométricos se o aluno não perceber que eles aparecem a todo instante, como em uma caixa de sapatos, por exemplo. Após visualizar, efetuará suas próprias conclusões e assim estabelecerá relações com suas experiências. Ademais,

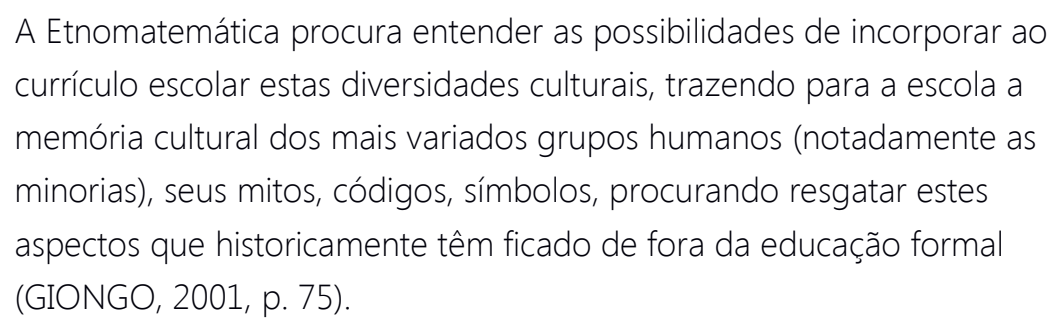

Considerando que a Etnomatemática busca compreender as diferentes culturas e as distintas formas de pensamento, D’Ambrósio (2002a, p. 19) aponta que o "domínio de duas etnomatemáticas, e possivelmente de outras, oferece maiores possibilidades de explicações, de entendimentos, de manejo de situações novas, de resoluções de problemas". Ainda para o autor, ao permitirmos o acesso de um número maior de instrumentos e técnicas contextualizadas, "muito maior capacidade de enfrentar situações e problemas novos, de modelar adequadamente uma situação real para esses instrumentos, chegar a uma possível solução ou curso de ação" (D'AMBRÓSIO, 2002a, p. 19).

\section{Procedimentos metodológicos}

Frequentemente, tem-se dado pouca ênfase ao ensino de Geometria na Educação Infantil. Ferreira (2004), em seus apontamentos sobre a utilização da Etnomatemática como recurso pedagógico, destaca que a "escola está fisicamente inserida num contexto social" fazendo com que a escola e os contextos "cresçam culturalmente" (FERREIRA, 2004, p. 80). Por sua vez, Monteiro (2004) retrata que a escola deve ser um espaço para edificação de uma educação "pautada pela ética elaborada pelos agentes nela envolvidos e comprometida pela diversidade" (MONTEIRO, 2004, p. 439).

Ao considerar o espaço escolar um local imerso de culturas distintas, percebemos que a pesquisa potencializa às crianças a garantia de um "espaço de descobertas, de proteção, de despreocupação, de vivência" (BUJES, 2002, p. 13). Do mesmo modo,

\footnotetext{
Minha relação concreta e direta com o campo da Educação Infantil tanto no plano acadêmico quanto institucional, tanto no campo dos discursos quanto das práticas pedagógicas propriamente ditas - passasse por um rigoroso processo de questionamentos e desestabilização para que eu pusesse em xeque a minha trajetória de pesquisadora moderna e fosse buscar num outro campo teórico as ferramentas que me permitissem identificar "minimamente" o que me inquietava (BUJES, 2002,
} 
p. 14).

Diante dessas inquietações, o presente estudo potencializou discussões do âmbito da Educação Matemática, buscando alicerce nos estudos da Etnomatemática. Tal ideia nos remete a outro aspecto apontado por Costa (2002) quando expressa que, embora não tenha um método único de pesquisa, "não significa que se possa fazer pesquisa sem método. O trabalho de investigação não pode prescindir de rigor e método, mas você pode inventar seu próprio caminho" (COSTA, 2002, p. 154). O caminho de que fala Costa (2002) está em consonância com as ideias de D’Ambrósio (2005) quando evidencia que na "[...] metodologia para trabalhar em Etnomatemática, o principal é a capacidade de observar e analisar as práticas de comunidades e populações diferenciadas, não necessariamente indígenas ou quilombolas ou de periferia" (D’AMBRÓsıO, 2005, p. 66). Ao considerarmos os pensamentos de D'Ambrósio (2005) e Costa (2002), entendemos que o estudo da Geometria Espacial na Educação Infantil é praticável e importante para o desenvolvimento das crianças da faixa etária de cinco e seis anos.

O contexto escolar em que a intervenção aconteceu, apesar de ser padronizado, abrangia indivíduos de diferentes contextos culturais. Em 2016, numa turma de Jardim B ${ }^{6}$ da escola em questão, percebemos a necessidade de possibilitar atividades que explanassem Noções Geométricas Espaciais e como o ambiente escolar e o bairro poderiam ser os pontos iniciais para o aprimoramento delas. A escola, Instituição de Educação Infantil, fora construída com verba federal, porém mantida pelo município de Bento Gonçalves. Localizava-se no bairro em função da demanda de crianças e pelo fato de os pais que a procuravam pertencerem à classe trabalhadora.

A turma em que foi efetivada a intervenção pedagógica, denominada Jardim B ${ }^{7}$, era constituída por dezoito crianças, das quais sete eram meninas e onze, meninos, sendo duas de inclusão. As profissões das famílias eram delimitadas por empregados de indústrias, comércio, autônomos, donas de casa, domésticas, entre outras.

Posto isso, apesentamos alguns resultados obtidos após aplicar atividades relacionadas a utensílios trazidos de casa pelas crianças. Neste artigo, explanamos um conjunto de saberes matemáticos advindos da análise do material empírico: filmagem das atividades, enunciações e materiais produzidos pelos estudantes.

\footnotetext{
${ }^{6}$ Crianças da faixa etária de cinco e seis anos de idade.

${ }^{7}$ A turma de Jardim B frequentava a escola no turno da tarde (13h30min às 17h30min).
} 


\section{Entre medidas e quantidades: emergência dos saberes matemáticos}

Assim, se as aprendizagens - em particular de conceitos matemáticos proporcionados, cabe ao professor de educação infantil instigar as crianças a pensar e questionar para, a partir daí, re(elaborar) conceitos e resoluções (CIMADON; GIONGO; SCHUWERTNER, 2017, p. 33).

Ao considerarmos os dizeres das autoras, compreendemos que a Educação Infantil possibilita a emergência de distintos saberes, e que a cultura das crianças está vinculada a suas diversas linguagens. De fato, passamos a perceber que elas operavam com conceitos matemáticos oriundos de suas vivências com seus familiares, especialmente os vinculados às Noções Geométricas Espaciais.

Os questionamentos realizados sobre as produções facilitaram a compreensão do que as crianças estavam explicitando em seus desenhos. Assim, possibilitou-nos perceber como utilizavam o desenho e as construções como forma de linguagem e de que maneira elas traziam consigo distintos saberes. Natividade et al. (2008, p. 16) expõem que, "por intermédio da verbalização sobre o desenho, é possível ter acesso tanto aos sentidos que o sujeito atribui à sua produção" e, por consequência, "à sua realidade, bem como investigar o modo como a linguagem participa no processo de desenvolvimento psicológico da criança" (NATIVIDADE et al., 2008, p. 16).

Para a atividade, as crianças tinham por tarefa trazer objetos de cozinha, buscando relação com seus conhecimentos e sobre as quantidades. Ao thes propor essa ideia e questioná-las se suas mães "mediam" as quantidades, a aluna A1 mostrou que o recipiente tinha "marquinhas". Quando indagadas o que seriam tais marcas, A3 logo respondeu:

A12 - São as coisas de medir.

A3 - É os ml.

Pesquisadora - E como você sabe que são os ml?

A3 - Porque é pra medi.

Pesquisadora - E quem te disse que isso são ml?

A3 - A minha mãe disse.

Pesquisadora - Muito bem! Nós vamos ver em qual cabe mais e qual cabe menos.

A8 - Isso aqui vai cabe muito menos ${ }^{8}$.

Pesquisadora - E por que você acha que vai caber pouco?

A8 - Porque ela é pequena.

Já na área externa, pegamos com uma xícara uma quantidade de areia conforme expresso na Figura 1. A ideia consistia em questioná-las sobre a quantidade e levá-las a

Referindo-se a uma colher de chá. 
estabelecerem relações com os utensílios que haviam trazido de casa, uma vez que a "capacidade é uma grandeza geralmente associada a um recipiente - ela se refere à porção do espaço que esse recipiente pode conter. Já o volume é associado à porção do espaço ocupada por um corpo" (FONSECA et al., 2002, p. 104).

Figura 1 - Xícara com quantidade de areia

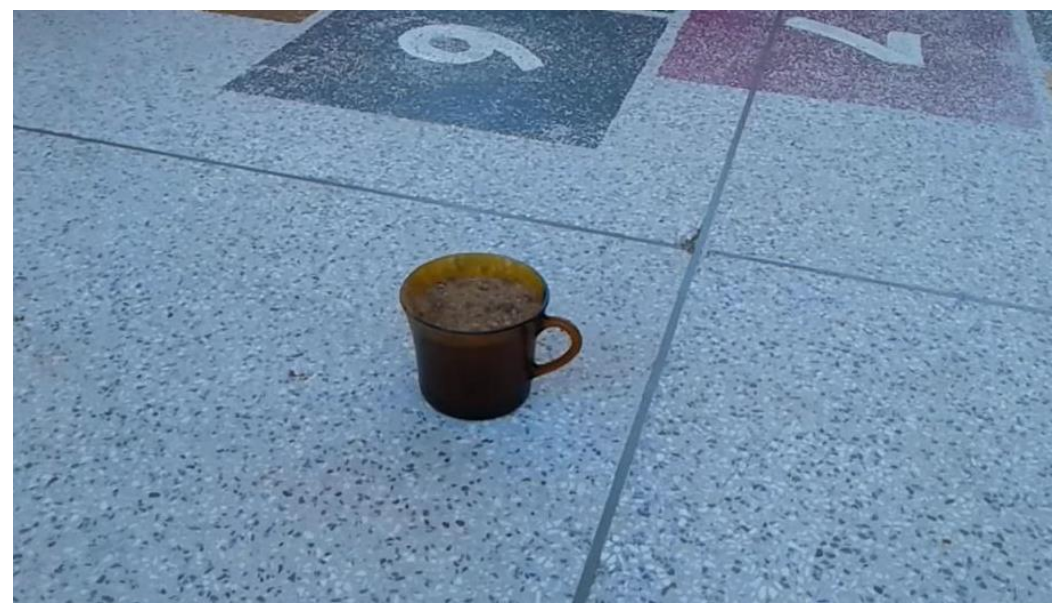

Fonte: Das autoras, 2017

Fonseca et al. (2002, p. 94) pressupõem que atividades relacionadas a práticas diárias têm por objetivo "provocar uma reflexão e uma discussão a respeito da presença da Geometria nas mais diversas situações de nossa vida pessoal". Assim, entendemos que os saberes das crianças emergem dessas vivências, motivo pelo qual thes propusemos o seguinte desafio:

Pesquisadora - Em quais objetos que vocês trouxeram cabe tudo isso aqui de areia?

A3 - O meu ${ }^{9}$.

Pesquisadora - E por que você acha que cabe?

A3 - Porque é retinho.

A16 - No meu.

Pesquisadora - E cabe tudo dentro do A16? Dá certinho, falta ou sobra espaço?

A15 - Falta areia. Porque o pote é grande.

De fato, ao chegarem à escola, as crianças já têm conhecimento intuitivo desse espaço perceptivo; elas exploram através de seus órgãos dos sentidos (FONSECA et al., 2002). Nessa parte da discussão, apresentaram dúvidas sobre suas colocações; assim, possibilitamos que experimentassem "medir" os utensílios e a areia. A criança A16 pegou seu pote e a xícara em que havia areia e realizou o teste (FIGURA 2).

\footnotetext{
${ }^{9}$ Referindo-se a uma tábua de cortar alimentos.
} 
Figura 2 - A16 testando quantidades entre utensílios

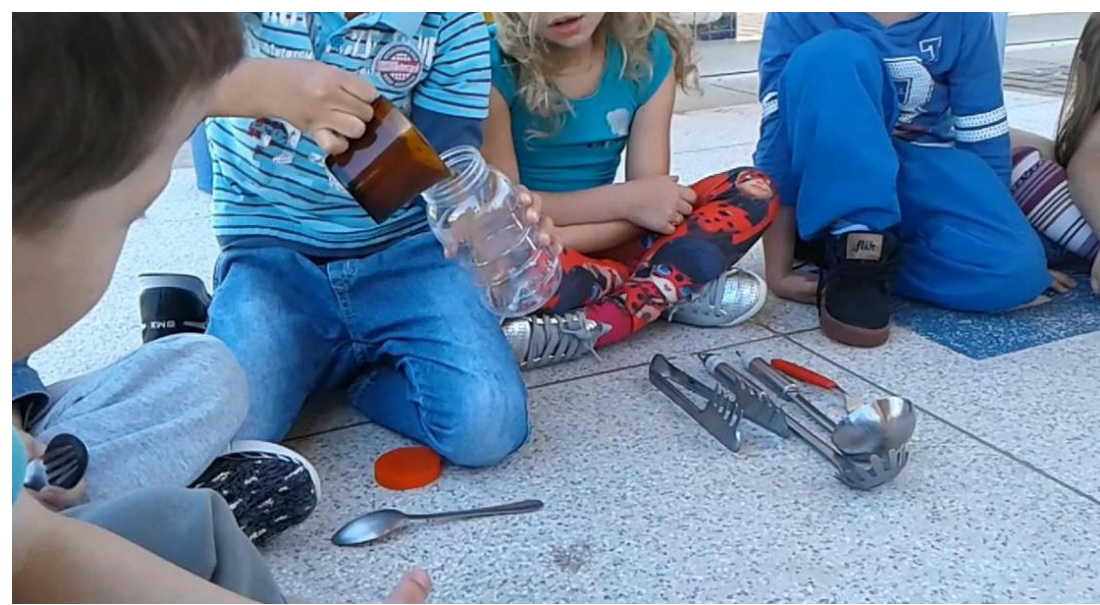

Fonte: Das autoras, 2017

Ao proporcionar às crianças que experienciem, é possível que elas melhorem "sua percepção espacial, visual e tátil, identificando as características geométricas desse espaço, apreendendo as relações espaciais entre objetos nesse espaço" (FONSECA et al., 2002, p. 47). Experimentando, elas perceberam que o pote de A16 era grande demais para a quantidade de areia que havia na xícara. Em vista disso, solicitamos que ela pegasse mais uma quantidade de areia no parque.

\section{Pesquisadora - Quantas xícaras nós colocamos? \\ A3 - Uma, mas eu acho que vai dar três. \\ Pesquisadora - Você acha que precisa de três para encher? A3 - Sim!}

Ao ouvirmos a resposta de $A 3$, compreendemos que o ensino da Geometria na Educação Infantil "deve contribuir para ampliar e sistematizar o conhecimento espontâneo que a criança tem do espaço em que vive" (FONSECA et al., 2002, p. 47). Assim, os conceitos de volume foram emergindo, levando à modificação e edificação de outros saberes. Após a criança colocar a segunda xícara de areia, A3, não satisfeito, logo apontou: "Precisa de mais uma!". Ao colocarem a terceira, questionamos se caberia mais uma; prontamente, disseram não. A aluna A15, ao perceber que uma inteira transbordaria no utensílio, afirmou:

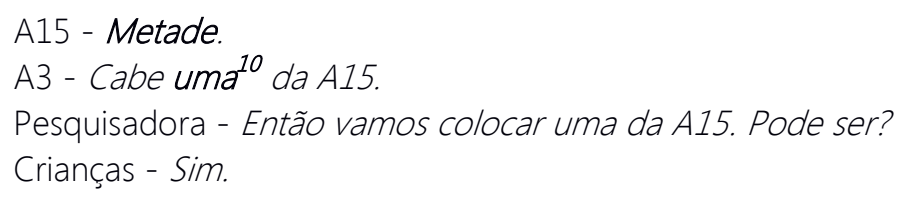

Antes de colocarmos a "xícara menor", solicitamos à A15 que dispusesse a quantia de areia que havia pegado dentro da "xícara maior". Logo após a distribuição, de forma espontânea, A3 afirmou: "Meia". Realmente, aparentava ser metade da maior, e, com essa

\footnotetext{
${ }^{10}$ Referindo-se a uma xícara menor da que estavam utilizando.
} 
resposta, compreendemos que as crianças conseguiram "perceber e organizar o mundo físico" (FONSECA et al., 2002, p. 47), e essas experimentações as levaram à "representação e à modificação desse espaço" (FONSECA et al., 2002, p. 47).

Pesquisadora - Então, quantas xícaras a gente precisa pra encher o pote do A16?

\section{A3 - Três e meia}

Nesse sentido, as crianças modificaram seus saberes mediante a discussão, pois começaram a se utilizar de expressões diferentes, ou seja, os saberes se transformaram, e novos conhecimentos foram apreendidos. A ideia de quantidade e onde ela cabe, baseada na percepção das crianças, vem de suas vivências, e estas, ao serem compartilhadas no grupo, contribuem para o aprimoramento das Noções Geométricas Espaciais.

Pesquisadora - E a areia que tem no pote do A16 cabe em algum outro utensilio?

A3 - Sim, no do A11, porque o dele é grande.

Por meio do teste, as crianças que apresentavam dúvidas puderam perceber que os potes maiores compactavam a quantidade que estávamos observando. Na Figura 3, é possível observar A11 tirando a "prova real" com relação à areia que estava no pote de A16.

Figura 3 - Criança A11 realizando teste na troca de potes

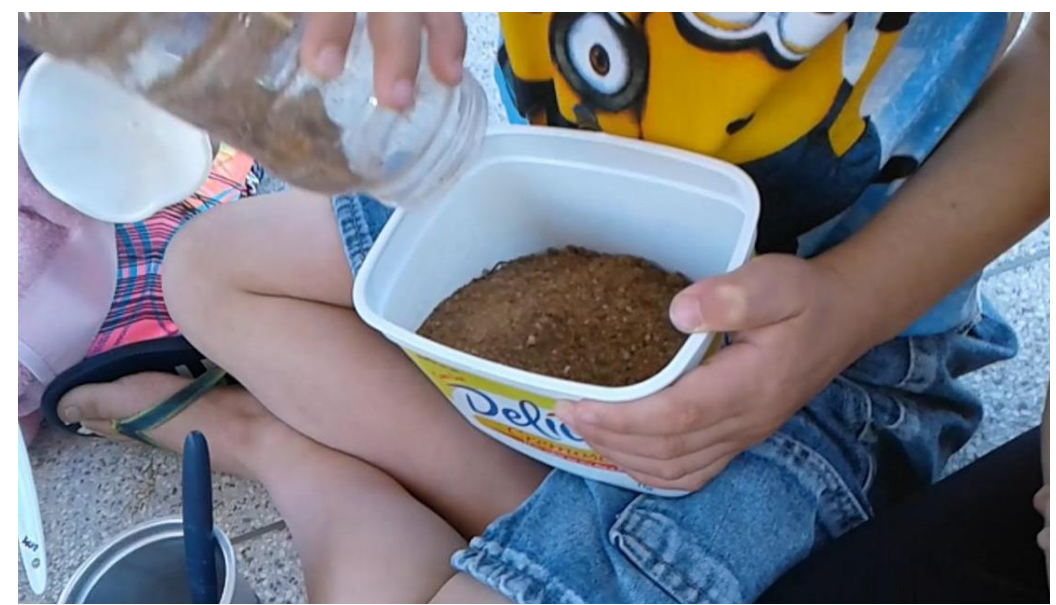

Fonte: Das autoras, 2017

Não satisfeito em comprovar que a areia cabia no pote, A3 logo apontou: "Deu meia!". Percebemos a capacidade de argumentação sobre a discussão, em que a criança, por ser espontânea e acreditar em seu potencial, expressou suas ideias e argumentos. O aluno A16 prontamente afirmou: "Precisa de mais uma!", evidenciando que a noção de volume estava presente em suas declarações, demonstrando o domínio do espaço no qual estávamos interagindo.

Percebendo que as crianças conseguiam apontar uma certa quantidade, propomos o seguinte desafio: "Em qual dos objetos que vocês têm cabem menos coisas?". Ato contínuo, A18 levantou sua colher, justificando: 


\section{A18 - Porque ele é desse tamanho! \\ A8 - A minha colher também!}

As crianças foram capazes de apontar que, quanto menor o objeto, menor a sua capacidade de armazenamento, também embasadas na noção de capacidade e volume. Pensando nisso, propusemos o seguinte questionamento:

Pesquisadora - Será que são quantas colheres de areia se a gente colocar de volta para o pote do A16?

A8 - Uma, duas, três....dez ${ }^{11}$.

Pesquisadora - Será que dá quantas?

A18 - Eu acho que tem vinte.

Pesquisadora - Vamos continuar.

Crianças - Onze, doze... vinte.

Pesquisadora - E se nós pegarmos a colher da A4, será que vai dar mais ou menos colheres?

A8 - Menos, porque a colher dela é maior.

Ao realizarmos a transposição, as crianças chegaram à conclusão de que a quantidade de areia que cabia no pote de A16 correspondia a vinte colheres de A8, ou três xícaras e meia de A15, ou meio pote de A11, ou onze colheres de A4. Elas realizaram diferentes transposições e discutiram as diversas capacidades dos utensílios. Ainda insatisfeitas com a discussão, propuseram colocar uma quantidade de areia no utensílio de $A 3$, uma tábua de corte (Figura 4).

Figura 4 - Transposição de uma certa quantidade de areia sobre a tábua de corte

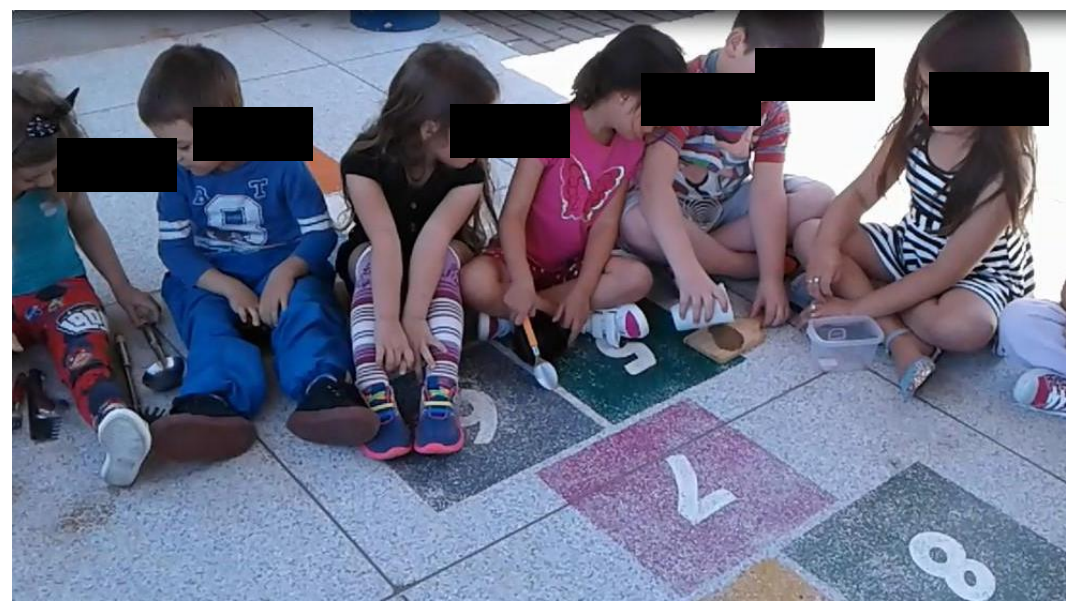

Fonte: Das autoras, 2017

A criança A3 tomou bastante cuidado ao dispor a areia em todos os cantos da tábua; porém, no momento em que o material ia transbordar, A18 logo apontou: "Está caindo um pouco de areia!" 


\section{Pesquisadora - Iiihhh, o que aconteceu? \\ A18 - Caiu um pouco de areia. \\ Pesquisadora - Mas por que cain areia? \\ A18 - Não têm essas coisinhas pra segurar ${ }^{12}$. \\ Pesquisadora - Mas o que são essas coisinhas? \\ A8 - É borda. \\ Pesquisadora - E como você sabe que é borda? \\ A8 - A minha mãe me explicou.}

Assim, constatamos que os saberes matemáticos foram emergindo em meio às discussões, mas que as aprendizagens oriundas de suas vivências familiares continuavam a aparecer. As crianças seguiam realizando suas comparações, trocavam ideias e experimentavam seus objetos de medidas. A contagem das quantidades foi utilizada como unidade de medida e, mesmo trocando de objeto, elas compreendiam que dependia do utensílio utilizado para saber a quantidade que cabia.

Ao retornarmos à sala, realizamos os mesmos questionamentos; porém, utilizando a água. As crianças puderam, de forma mais independente, estabelecer comparações nas transposições de recipiente para recipiente e a contagem presente em suas interações. Na Figura 05, é possível observar A18 realizando a transposição por meio da colher, utilizandoa como unidade de medida.

Figura 05 - A18 utilizando a colher como unidade de medida

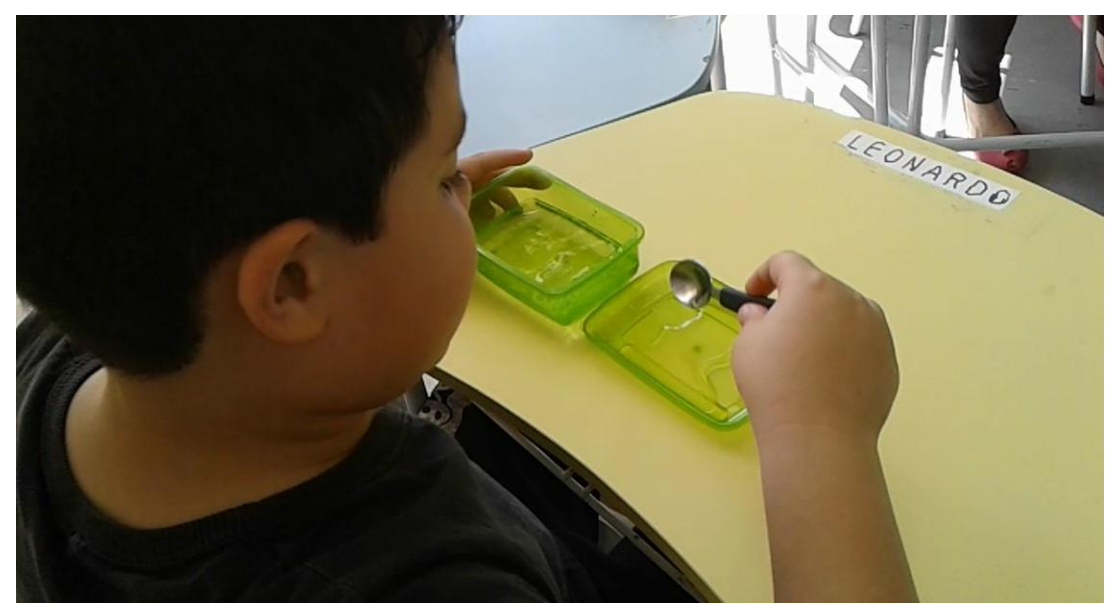

Fonte: Das autoras, 2017

Ao examinarmos atentamente os saberes emergentes por meio da Etnomatemática e dirigirmos um olhar especial sobre suas compreensões matemáticas, compreendemos que as crianças pertenciam a distintos meios culturais. A forma como se expressavam e construíam evidenciava conhecimentos de sua vida diária; no ambiente escolar, a interação possibilitou a reestruturação de outros conceitos. A seguir, abordamos algumas considerações sobre os apontamentos realizados durante a análise do material.

\footnotetext{
${ }^{12}$ Referindo-se à falta das paredes (faces).
} 


\section{Considerações Finais}

A pesquisa efetivada nos mostrou a potência de operar com os referenciais teóricometodológicos do campo da etnomatemática nos processos de ensino na Educação Infantil. De fato, compreendemos que as crianças fazem uso de estratégias usualmente ausentes no contexto escolar quando confrontadas com demandas relativas à Geometria, sobretudo espacial. Cabe também destacar que, frequentemente, o conteúdo de Geometria, quando abordado na Educação Infantil, se restringe à plana, com destaque para o estudo de formas e composição de algumas figuras. Entretanto, a BNCC (BRASIL, 2017) retrata que as crianças têm direito de ampliar as competências que consolidam os direitos de aprendizagem e desenvolvimento. Sendo assim, os educandos precisam

Exercitar a curiosidade intelectual e recorrer à abordagem própria das ciências, incluindo a investigação, a reflexão, a análise crítica, a imaginação e a criatividade, para investigar causas, elaborar e testar hipóteses, formular e resolver problemas e criar soluções (inclusive tecnológicas) com base nos conhecimentos das diferentes áreas (BRASIL, 2017, p. 9).

A investigação nos permitiu constatar a necessidade de despertar no aluno competências que contribuam para o seu olhar crítico, bem como a unificação das distintas áreas de conhecimento. A BNCC também atenta para que se valorize "a diversidade de saberes e vivências culturais" (BRASIL, 2017, p. 9), garantindo, assim, que os saberes possam ser expressos e viabilizem a edificação de outros. Logo, essa "diversidade" de culturas contribui para as crianças passarem a "conhecer a si e ao outro e de conhecer e compreender as relações com a natureza, com a cultura e com a produção científica" (BRASIL, 2017, p. 37). À vista disso, atrevemo-nos a afirmar que a cultura é inerente ao sujeito e não podemos desconsiderá-lo.

Ao analisarmos o resultado da prática investigativa, é significativo descrever algumas considerações acerca da pesquisa que possibilitaram sanar as inquietações, mas também efetivar que a "cultura se manifesta no complexo de saberes/fazeres, na comunicação, nos valores acordados por um grupo, uma comunidade ou um povo. Cultura é o que vai permitir a vida em sociedade" (D'AMBRÓSIO, 2002b, p. 59). Pensamos que foi esse o propósito, visto que a preocupação estava centrada nos processos de ensino e de aprendizagem da Geometria Espacial baseados nas experiências culturais na Educação Infantil.

Acreditamos, ao final desta escrita, que a pesquisa provocará inquietudes em outros professores e, por consequência, percebam como as habilidades e competências, nas distintas áreas do conhecimento, podem ser proporcionadas a nossas crianças. Em nós, provocou a necessidade de seguir pesquisando no âmbito da Geometria presente nas distintas culturas, sobretudo em classes com estudantes oriundos de outros países. Em efeito, por conta do crescente número de crianças imigrantes nas salas de aulas gaúchas, sobretudo filhos de imigrantes haitianos e africanos, nos engajamos numa investigação que 
pretende compreender como estes fazem uso de regras geométricas em suas práticas cotidianas. A partir de então, será importante examinar como tais regras podem ser produtivas para os processos de ensino e de aprendizagem na Escola Básica.

\section{Referências}

BRASIL. BNCC (2017). Base Nacional Curricular Comum. Disponível em: <http://basenacionalcomum.mec.gov.br/images/BNCC_20dez_site.pdf>. Acesso em: 15. dez. 2017.

BUJES, Maria Isabel Edelweiss. Descaminhos. In: COSTA, Marisa Vorraber et al. (Org.) Caminhos Investigativos II: Outros modos de pensar e fazer Pesquisa em Educação. Rio de Janeiro: DP\&A, 2002.

CIMADON, Ediana; GIONGO, Ieda Maria; SCHWERTNER, Suzana F. A Etnomatemática na Educação Infantil. Revista Pátio Educação Infantil, Porto Alegre, Ano XV, n. 50., jan/mar. 2017, p. 32-35.

COSTA, Marisa Vorraber et al. Caminhos Investigativos: Novos Olhares na Pesquisa em Educação. 2. Ed. Rio de Janeiro: DP\&A, 2002.

D' AMBROSIO, Ubiratan. Etnomatemática e Educação. In. OLIVEIRA, Cláudio José de; VIEGAS, Moacir Fernando. (Orgs.). Etnomatemática currículo e formação de professores. Santa Cruz do Sul: EDUNISC. v. 10, n. 1, p. 7-19, jan./jun. 2002a.

D' AMBROSIO, Ubiratan. Etnomatemática: arte ou técnica de explicar e conhecer. 5. ed. São Paulo: Ática, 1998.

D' AMBROSIO, Ubiratan. Etnomatemática: Elo entre as tradições e a modernidade. 2. ed. Belo Horizonte: Autêntica, 2002b.

D'AMBROSIO, Ubiratan. O programa Etnomatemática como uma proposta de reconhecimento de outras formas culturais. 2. Santa Fé: Yupana, 2005. Disponível em:<http://bibliotecavirtual.unl.edu.ar/ojs/index.php/Yupana/article/view/245/326>. Acesso em: 10 dez. 2016.

DIENES, Zoltán Pál; GOLDING, William. Primeiros Passos em Matemática: Exploração do espaço e a prática da medição. São Paulo: Herder, 1969.

DUHALDE, Maria Elena; CUBERES, Maria Teresa Gonzáles. Encontros Iniciais com a Matemática: Contribuições à Educação Infantil. Porto Alegre: Artes Médicas, 1998.

FAINGUELERNT, Estela Kaufman. Educação Matemática: Representação e Construção em Geometria. Porto Alegre: ARTMED. 1999.

FERREIRA, Eduardo Sebastiani. Os índios Waimiri - Atroari e a etnomatemática. In: KNINIK, Gelsa; WANDERER, Fernanda; OLIVEIRA, Cláudio José de. (Orgs.). Etnomatemática, currículo 
e formação de professores. Santa Cruz do Sul: Edunisc, 2004, p. 70-88.

FONSECA, Maria da C. F. R. et al. O Ensino de Geometria na Escola Fundamental: Três questões para a formação do professor dos ciclos iniciais. 2. Ed. Belo Horizonte: Autêntica, 2002.

GIONGO, Ieda M. Educação e Produção do Calçado em Tempos de Globalização: um estudo etnomatemático. 2001. Dissertação (Mestrado em Educação) - Universidade do Vale do Rio dos Sinos, São Leopoldo, nov. 2001.

KNIJNIK, Gelsa; WANDERER, Fernanda; GIONGO, Ieda M.; DUARTE, Claudia G.

Etnomatemática em movimento. Belo Horizonte: Autêntica, 2012.

KNIJNIK, Gelsa. Itinerários da Etnomatemática: questões e desafios sobre o cultural, o social e o político na educação matemática. In: KNIJNIK, Gelsa; WANDERER, Fernanda; OLIVEIRA, Cláudio José de. (Orgs.). Etnomatemática, currículo e formação de professores. Santa Cruz do Sul: Edunisc, 2004, p. 19-38.

MONTEIRO, Alexandrina. A etnomatemática em cenários de escolarização: alguns elementos de reflexão. In: KNINIK, Gelsa; WANDERER, Fernanda; OLIVEIRA, Cláudio José de. (Orgs.). Etnomatemática, currículo e formação de professores. Santa Cruz do Sul: Edunisc, 2004, p. 432-446.

NATIVIDADE, Michelle Regina da.; COUTINHO, Maria Chalfin; ZANELLA, Andréa Vieira.

Desenho na pesquisa com crianças: análise na perspectiva histórico-cultural. vol. 1, n. 1. UNISINOS: Contextos Clínicos, jan./jun. 2008.

SMOLE, Kátia S.; DINIZ, Maria I.; CÂNDIDO, Patrícia. Figuras e formas: Matemática de 0 a 6 anos. 3. v. Porto Alegre: Artmed, 2003.

ZOGAIB, Simone Damm; SANTOS-WAGNER, Vânia Maria Pereira dos. Entre caixas, bolas e bambolês: a orientação espacial na educação infantil. Brasília: Educação Matemática em Revista, v. 22, n. 53, p. 51-61, jan./mar. 2017. 